\title{
Features of teaching students with motor skills disorder caused by hearing loss
}

\author{
Elena Mamedova ${ }^{1}$, Marina Skuratovskaya ${ }^{2 *}$, and Natalia Grash ${ }^{1}$ \\ ${ }^{1}$ The Herzen State Pedagogical University of Russia, 197046, St. Petersburg, Russia \\ ${ }^{2}$ Don State Technical University, 344000, Rostov-on-Don, Russia
}

\begin{abstract}
This study analyses various disorders of general motor skills, voluntary finger movement, and articulatory motor skills of school-aged children with hearing loss. The analyzed disorders of the motor sphere of schoolchildren with auditory deprivation are not of a pronounced character but are one of the reasons for their lag in psychophysiological and speech development. The results of studies that reveal specific motor difficulties of deaf primary schoolchildren are considered. The role of dysfunction of the vestibular system in movement disorders in children with hearing impairment has been determined. Particular attention is paid to the consideration of the complex possibilities of correctional and developmental work of educational institutions for deaf children to overcome motor development disorders of deaf primary schoolchildren. The role of complex correctional and developmental work at the initial stage of school training in educational institutions for deaf children has been determined. The possibilities of using computer technologies as an effective resource in the motor and speech development of young schoolchildren with hearing impairment are shown.
\end{abstract}

\section{Introduction}

According to $\mathrm{WHO}$, more than $5 \%$ of the world's population - 466 million people (432 million adults and 34 million children) have hearing impairment of various etiologies and degrees of impairment. Among this category, most persons with a sensorineural nature of auditory deprivation. Currently, there is a tendency towards rejuvenation of the disorder. More than 1 million children with hearing impairment are registered in the Russian Federation. There is an increase in the number of children with hearing impairment, especially in the age group after three years. Obviously, the study of this category of persons is relevant in medical, social, psychological, and pedagogical terms. A significant decrease (more than $60 \mathrm{~dB}$ ) or loss of hearing by a child at an early age causes the originality of the formation of the physical, speech, emotional, volitional components of his personality. As L. S. Vygodsky, the primary impairment of the auditory analyzer is caused by biological factors, leads to the underdevelopment of the higher mental functions of speech and thinking. Difficulties in verbal communication limit the possibilities of obtaining external information

\footnotetext{
* Corresponding author: marinasku@yandex.ru
} 
and cause the peculiarities of all cognitive activity in general. Special attention to the problem of hearing impairment in childhood is since the development of his verbal speech and the possibility of successful adaptation in the surrounding society depend on the level of hearing loss, the time of occurrence of the impairment, pedagogical and individual characteristics of the child. It is obvious that the full development of the motor skills of children with hearing impairment is the starting point in the development of the basic psychomotor functions of a child - motor, cognitive, emotional and speech.

The state of development of the motor sphere of children with problems of auditory development determines the possibility of mastering movements of different complexity. These are movements associated with the development of modes of movement, self-service skills, educational and labor activities at school age, etc. The full development of the movements of a child with hearing impairment is his vital need.

\section{Theoretical Basis}

The expediency of improving the motor skills of children with hearing impairment to compensate for disorders of not only motor, but also cognitive development has been repeatedly emphasized by many Russian scientists and scientists from around the world: N. I. Stepanchenko, I. B. Hrybovska, M. V. Danylevych, R. V. Hryboskyy, Esther Hartman, Suzanne Houwen, Chris Visscher, F. Gheysen, G. Loots, H. Van Waelvelde, M. Sokolov, K.A. Gordon, M. Polonenko, S.I. Blaser, B.S. Papsin, S.L. Cushing Cushing, and many others [1-4]. In most studies, a direct link is shown between the dysfunction of the child's auditory analyzer and the development of his motor sphere.

The development of the motor sphere takes many years - from infancy to school age. In young children with hearing impairment, many movements appear at first as congenital. Gradually, as the child develops, they become the result of learning. Several studies have analyzed the process of such a transition. Children of the first days of life have an innate grasping reflex, which gradually fades away by the end of the first month. By the 4th month, the grasping movement appears again. This is since the child begins to reach for objects and grab them. In the second case, the grasping movement is the result of learning. This and other facts indicate that children master movements gradually through learning, which is confirmed by some studies [5]. The child acquires the ability to sit, stand, move in space and other complex motor acts with the direct participation of adults. Children with auditory deprivation and without sensory impairments have a general tendency to develop the motor sphere. However, a violation of the sensory system causes specific abnormalities in the development of motor skills. A few works on child physiology are focused on determining the importance of work on the development of the motor sphere of children of this nosological group in preschool and early school age, when all the basic systems and functions of the body continue to form $[5,6,7]$.

Specially conducted research aimed at identifying the features of the motor sphere of younger schoolchildren with hearing impairment show the discrepancy between the level of movement of deaf children and age norms. There is a lag in the development of all components of the motor sphere: general motor skills, voluntary motor skills of the fingers, facial and speech (articulatory) motor skills. Interesting data are presented in the works $(\mathrm{H}$. Hasanbegović, S. Mehmedinović, H. E. Mahmutović, M. S. Houde, S.P. Landry, S. Pagé, M. Maheu, F. Champou, etc.), they reveal the close connection and dependence of all components of the motor sphere of a child with hearing impairment $[7,8]$.

Research of general motor skills (movements of arms, legs, trunk) of children with severe hearing impairment reveal general motor impairment: changes in gait, disorder of coordination of large and small movements (motor skills), disturbances in static and dynamic balance. When performing complex movements, awkwardness and inaccuracy appear, 
difficulties in static and dynamic coordination, in the speed and strength of movements, in keeping the body in each position, in poor coordination of body parts when performing complex movements, inability to navigate in space $[5,8,9]$. The researchers note that deaf children show the lowest results in the development of general motor skills in the development of static coordination. Revealed great difficulties in maintaining balance and maintaining a posture in the body in space. Children cannot hold the position for a long time without changing the position of the legs to a more stable one. The maximum holding time of the body in each position is no more than four minutes. Indicators of movement speed are at a low level. In most cases, children perform movements at a slow pace. Complex movements associated with the sequence of execution cause them special difficulties. Deaf students need time to comprehend them, which leads to a decrease in the speed of the movement itself. Significantly better indicators are noted in the study of dynamic praxis. However, the results of these tests are lower than those of normally developing children [10]. Researchers observe a lack of rhythm in the actions of children, a violation of the sequence of steps of the right and left legs, the sequence of the clap and step. Difficulties of this kind in performing movements (dynamic praxis) lead to a decrease in the speed of their implementation. Attention is drawn to the fact that many children with hearing impairments find it difficult to maintain balance when jumping on two legs and one leg. Performing a jump, they land on their entire foot, perform a rough forward tilt of the body. Research results show that the best indicator when examining the general motor skills of children with hearing impairment is the indicator of the strength of movements. The facts confirm the correspondence of the level of strength of movements of children with hearing impairment to the level of normally developing peers. The muscular efforts of deaf children are at a high level and the tasks of tests for the examination of this indicator of general motor skills do not cause any difficulties for them. Research authors of general motor skills (movements of arms, legs, trunk) of children with severe hearing impairment reveal general motor impairment: changes in gait, disorder of coordination of large and small movements (motor skills), disturbances in static and dynamic balance. Found that when deaf children perform general motor movements, the appearance of concomitant movements. Most children accompany voluntary movements by raising their eyebrows, protruding their tongue, additional sounds, squint your eyes $[6,7,10]$.

Most researchers agree that the worst children of this nosological group cope with tasks for coordination of movements. A low level of coordination of movements of both arms and legs was revealed. Most children with auditory deprivation make mistakes in coordination movements. The main difficulties are associated with the coordination of the body in space, keeping the body in a certain position, maintaining body balance [11].

Summarizing the research data, we can talk about the presence of various disorders in the development of the general motor skills of deaf students: inaccurate coordination and uncertainty in movements, which are manifested in the form of a shuffling gait; low rate of mastering general motor skills; the difficulty of maintaining statistical and dynamic equilibrium; low level of development of orientation in space; low rate of performance of individual movements.

When studying the voluntary motor skills of the fingers of deaf junior schoolchildren in the research works of Paulina Yesica Ochoa Martínez et al., a slight lag normally developing peers was shown [12]. However, impairment of the auditory system causes some specific difficulties in static and dynamic coordination of the fingers, kinesthetic and dynamic praxis, the ability to oppose the thumb to the rest, visual-motor coordination.

Observations of how hearing-impaired children know how to dress and undress, how to unfasten and fasten buttons, untie, and tie their shoelaces, convinced researchers that this category of schoolchildren has certain drawbacks when performing such simple everyday activities. The presence of movement disorders associated with changes in muscle tone, low 
speed of movements, which changes during the action, are noted. The irrational distribution of efforts during the movement was revealed. Children need a lot of time to unroll and collect small items, turn the pages of books. Many researchers note the presence of motor awkwardness when performing tasks of this kind: the movements of the fingers are tense, irregular; fixation of the posture is noted; when changing a pose, actions are performed abruptly, abruptly. In some schoolchildren, in the presence of hypertonia, synkinesis with the fifth finger is traced. When performing a series of movements, their amplitude and speed decreases, gradual relaxation of the fingers and lowering of the hand are noted. Specially conducted studies have shown that the hand-eye coordination of deaf primary schoolchildren, as well as in a significant part of normally developing peers, is insufficiently developed $(\mathrm{R}$. M. Kamel, S. M. Mounir, M. A. Elbedewy, M. M. Essa, L. A. Fergany, E. S. Mehrem, D. L. Horn, D. B. Pisoni, R.T. Miyamoto, etc.) $[13,14]$. Deaf children do not always manage to pass the labyrinths quickly and accurately with their right and left hands, put dots on paper, draw the given lines correctly, pierce holes in a sheet of paper with circles printed on it (Rossolimo attention test form). Some schoolchildren with hearing impairment, difficulties were identified when cutting a mug out of paper. This is due to the inherent rotation and twisting problems of individual fingers and the wrist. Researchers note the presence of replacements for such delicate movements of the fingers, movements of the entire hand [15].

Summarizing the research data, we can talk about the presence of disorders in the development of voluntary motor skills of the fingers of younger schoolchildren with auditory deprivation: low accuracy, speed, differentiation of movements; difficulty in performing a series of movements; insufficient level of development of hand-eye coordination; difficulties with the simultaneous execution of movements; slow pace.

Examination of the state of articulatory and mimic motility of schoolchildren with hearing impairment revealed significant impairment here. There is a lag in the development of kinesthetic oral (articulatory) praxis, underdevelopment of kinetic oral praxis, difficulties in the dynamic coordination of articulatory movements. There is an underdevelopment of facial muscles, a violation of the mobility of the lips and an increase in the muscle tone of the tongue.

The development of the articulation skills of a child with hearing impairment is the starting point in the work on oral speech. The absence of speech or its insignificant development at the preschool and early school stages of a deaf child's education explains the low level of development of his articulatory skills [16,17].

It should be noted that hearing impaired junior students are a complex and diverse category. Depending on the degree of hearing impairment, the possibilities for the formation and development of oral speech, and, consequently, the development of articulatory motor skills, depend.

Table 1. Possibility of developing oral speech by a child with auditory deprivation, depending on the degree of hearing impairment at the age of up to 5 years.

\begin{tabular}{|c|c|c|c|}
\hline $\begin{array}{c}\text { Degree of } \\
\text { hearing } \\
\text { impairment }\end{array}$ & $\begin{array}{c}\text { Description of the } \\
\text { degree of hearing } \\
\text { impairment }\end{array}$ & $\begin{array}{c}\text { Opportunities for } \\
\text { mastering oral } \\
\text { speech }\end{array}$ & $\begin{array}{c}\text { Using oral speech in } \\
\text { communication }\end{array}$ \\
\hline I & $\begin{array}{c}26-40 \mathrm{~dB} \\
\text { The child cannot hear } \\
\text { quiet sounds, difficulties } \\
\text { in understanding speech } \\
\text { in a noisy environment }\end{array}$ & $\begin{array}{c}\text { Can independently } \\
\text { master oral speech } \\
\text { with minor errors }\end{array}$ & $\begin{array}{c}\text { Actively uses oral } \\
\text { speech in } \\
\text { communication }\end{array}$ \\
\hline II & $\begin{array}{c}41-55 \mathrm{~dB} \\
\text { The child cannot hear } \\
\text { soft sounds and sounds }\end{array}$ & $\begin{array}{c}\text { Can independently } \\
\text { master oral speech }\end{array}$ & $\begin{array}{c}\text { Inactively uses oral } \\
\text { speech in } \\
\text { communication }\end{array}$ \\
\hline
\end{tabular}




\begin{tabular}{|c|c|c|c|}
\hline & $\begin{array}{l}\text { of medium volume, } \\
\text { there are significant } \\
\text { difficulties in } \\
\text { understanding speech, } \\
\text { especially with } \\
\text { background noise }\end{array}$ & $\begin{array}{l}\text { with significant } \\
\text { errors }\end{array}$ & \\
\hline III & $\begin{array}{c}56-70 \mathrm{~dB} \\
\text { The child cannot hear } \\
\text { most of the speech } \\
\text { sounds that are spoken } \\
\text { by a voice at a speaking } \\
\text { volume }\end{array}$ & $\begin{array}{l}\text { Independent mastery } \\
\text { of oral speech is } \\
\text { almost impossible, } \\
\text { special corrective } \\
\text { work is required }\end{array}$ & $\begin{array}{l}\text { Does not use oral } \\
\text { speech in } \\
\text { communication. } \\
\text { Formation of oral } \\
\text { communication is } \\
\text { possible only in the } \\
\text { context of special } \\
\text { training }\end{array}$ \\
\hline IV & $\begin{array}{l}71-90 \mathrm{~dB} \\
\text { The child can only } \\
\text { distinguish very loud } \\
\text { sounds. }\end{array}$ & $\begin{array}{l}\text { Cannot master oral } \\
\text { speech on his own, } \\
\text { special corrective } \\
\text { work is required }\end{array}$ & $\begin{array}{l}\text { Does not use oral } \\
\text { speech in } \\
\text { communication. } \\
\text { Formation of limited } \\
\text { oral communication is } \\
\text { possible only in the } \\
\text { context of special } \\
\text { training }\end{array}$ \\
\hline Deafness & $\begin{array}{c}\text { Over } 90 \mathrm{~dB} \\
\text { The child can only } \\
\text { distinguish very loud } \\
\text { high-frequency sounds } \\
\text { (the spectrum of } \\
\text { perceived frequencies is } \\
\text { often limited) }\end{array}$ & $\begin{array}{l}\text { Cannot master oral } \\
\text { speech on his own, } \\
\text { special corrective } \\
\text { work is required }\end{array}$ & $\begin{array}{l}\text { Does not use oral } \\
\text { speech in } \\
\text { communication. } \\
\text { Formation of limited } \\
\text { oral communication is } \\
\text { possible only in the } \\
\text { context of special } \\
\text { training }\end{array}$ \\
\hline
\end{tabular}

In the act of speaking, a normally developing child selects the words necessary for expressing thoughts, grammatically formalizes them and pronounces them through the articulatory movements of the speech organs. With auditory deprivation, the speech mechanism cannot function in this way. Research shows that with hearing loss up to 3-5 years, the speech development of children with III and IV degrees of impairment, as well as the diagnosis of deafness, stops at the earliest stage of speech development. The child's speech reactions gradually fade away and stop. From this moment on, the articulatory movements that are needed to improve oral speech normally do not develop independently in deaf children, and they need special help to continue their speech development. The scientific works of P. K. Anokhin et al. Show that the psychophysiological mechanism of speech of persons with severe hearing impairment is based only on speech and motor skills, which do not include (or include insignificantly) the auditory component [18].

Thus, the improvement of the articulatory motor skills of this group of schoolchildren provides the opportunity for their speech development.

In scientific works that study the development of articulatory motor skills in younger deaf schoolchildren, the lack of formation of oral praxis, tremor of the organs of articulation (tongue), partial paresis, decreased or increased tone of the muscles of the tongue, and accompanying movements are shown. In children with hearing impairment, statodynamic sensations are not formed, there are no clear articulatory movements and kinesthetic images of movements of the articulatory muscles. Schoolchildren have serious difficulties with the 
formation of tactile sensations: the duration and smoothness of the air stream; brevity and duration of articulation; vibration or lack of vibration of the larynx when pronouncing sounds; narrow, wide, warm, cold stream of air when pronouncing speech sounds. In articulatory movements, insufficient strength of movements, inaccuracy, incomplete volume, slow switching from one movement to another are revealed. Researchers show that a typical mistake in the articulation of deaf children is the simultaneous inclusion of the lower lip and jaw in the motor act. Schoolchildren experience difficulties in performing movements that require a quick change in the position of the tongue, which indicates a violation of the dynamic coordination of movements (raise and lower the narrow tip of the tongue, raise the lateral edges of the tongue, and relax the tongue, etc.). When performing complex articulatory movements, children cannot repeat the given position of the lips or tongue and take the articulatory position gradually. Difficulties in maintaining the articulatory position and premature exit from it are noted [16].

Further studies of facial expressions by N. Baudonck, K. Van Lierde, I. Dhooge, P. Corthals and others allowed scientists to identify several specific difficulties in children with hearing disorders. Schoolchildren cannot freely raise their eyebrows, squint your eyes, tightly compressed lips, raise their lower and upper lips and show their teeth, etc. $[17,18]$.

\section{Results}

Summarizing the research data, we can talk about the presence of impairments in the development of articulatory motor skills in children with auditory deprivation: low speed and accuracy of movements, difficulties while performing movements at the same time; slow pace. The researchers note that the difficulties of children in performing articulatory movements are so varied that it is extremely difficult to identify characteristic errors.

Thus, it can be concluded that the motor sphere of younger schoolchildren with hearing impairment is insufficiently developed. There is a lag the motor development of normally developing children in general motor and articulation skills. Some difficulties schoolchildren experience when performing voluntary movements of the fingers. Summarizing scientific research on the problem of the development of the motor sphere of deaf schoolchildren, it is possible to identify specific motor difficulties of this category of children: low level of orientation in space; a low rate of mastering motor skills; difficulty in maintaining static and dynamic balance; inaccurate coordination of movements; low speed of movement; the difficulty of keeping the body and organs of articulation in a certain position; difficulty in performing mimic movements; difficulty maintaining the balance of the body in space. An analysis of the above specific difficulties experienced by schoolchildren with hearing impairment when performing a variety of actions suggests that motor skills of coordination of movements, spatial position and maintaining balance are the worst developed. Russian scientists and scientists around the world (E. Verbecque, T. Marijnissen, N. De Belder, V. Van Rompaey, A. Boudewyns, J. Vitkovic, R. A. Clark, etc.) emphasize that hearing impairment is closely related to disorders of the vestibular apparatus, which, in turn, leads to the appearance of specific changes in the motor sphere of children of this nosological group $[19,20]$.

The auditory and vestibular analyzers are in close anatomical interaction. The spiral cavity of the inner ear containing the organ of Corti, which produces nerve impulses in response to sound vibrations. The vestibular analyzer is a sensory system that reacts to changes in the external and internal environment of the body. The main function of the vestibular apparatus is to integrate the entire complex of spatial control systems. As a result of such control, a person catches changes in the position of the body in space, changes in the direction of gravity, the amount of inclination of the body, and acceleration of movement. The vestibular system is one of the main systems that stabilizes the center of gravity of the 
body. The vestibular apparatus provides balance and controls the condition of the musculoskeletal system. In the research of scientists, much attention is paid to the study of the role of the vestibular analyzer in sensations of the position of the head, body, and direction of movement. It is shown that changes in body position and movements are simultaneously analyzed by visual, skin and motor analyzers. Impulses from all receptors (vestibular, skin, muscle, visual) go to the cerebral cortex, where they interact. The vestibular system relates to the cerebellum and spinal cord, which provide its main function - a static feeling, which serves to determine the position of the body and its parts and to maintain the necessary actions during movement [19].

Researchers studying the pathology of the vestibular analyzer associate impaired coordination of movements, balance, and a decrease in the ability to maximize motor qualities in deaf children with disorders of the vestibular system. With an increase in motor load, specific difficulties appear in the movements of younger deaf schoolchildren. Performing complex movements causes a violation of spatial orientation. Researchers have observed imbalance, unstable gait, poor coordination of limb movements. Some schoolchildren cannot hold a given hand position, connect fingers on one and both hands, simultaneously deflect both hands, etc. In the development of articulatory motor skills, these are difficulties with changing the spatial position of the lips and tongue in the oral cavity and outside it [20].

So, as evidenced by the results of studies in the field of vestibular disorders in schoolchildren with auditory deprivation, all types of coordination abilities in this category of children are impaired. This negatively affects the formation of motor skills in deaf schoolchildren. This circumstance determines the need for special corrective measures to eliminate the manifestations of coordination disorders.

\section{Discussion}

When a child with hearing impairment enters a school educational institution, a new period in his development begins. The transition from preschool educational institution to school is an important moment in the overall development of children. The main activity of a deaf child is learning activity, which determines the development of all mental properties and qualities. During this period, the active physical and psychophysiological development of the child with auditory deprivation continues. Many researchers note that at primary school age children have large reserves of development (Paulina Yesica Ochoa-Martínez, Clévia Barboza, Alex Ramos, Paula Abreu, Helena Castro, etc.) [21,22].

Intensive physical and mental development takes place, which provides the opportunity for systematic education at school. Children's physiologists say that by the age of 7 , the child's cerebral cortex and nervous system are improving. A significant increase in musculature and muscle mass begins, a significant increase in muscle strength occurs. Significant changes in physical development determine an increase in the mobility of younger schoolchildren with hearing impairment. General motor skills begin to develop especially actively. Children tend to run, jump, climb more and, at the same time, there are difficulties in the child's stay in the same position for a long time. Significant changes occur not only in the physical, but also in the mental development of children with hearing impairment: the cognitive sphere changes qualitatively, the personality is formed, and cognitive development occurs [21].

The active psychophysical development of a student with hearing impairment is mainly associated with the implementation of complex correctional and developmental work, which is carried out in educational institutions for deaf children. Optimal conditions are created to ensure the education and upbringing of a deaf child. At the first stage of special school education, the continuity of correctional and developmental work is ensured, which is implemented through the content of educational areas, extracurricular activities and through 
special classes in the correctional and developmental area. The purpose of correctional and developmental work is to provide comprehensive assistance to schoolchildren with hearing impairment in mastering the main general educational program of primary general education, developing vital competence, integrating normally hearing peers into the environment. A special place in the work with younger deaf schoolchildren is given to the correction of deficiencies in the physical and (or) mental development of the child, which ensures the gradual improvement of their motor skills. Correctional and developmental work is carried out with the purposeful and systematic formation and development of verbal speech, as a means of personal development of a deaf child and a means of communication with the hearing. The ratio of oral, written, oral-dactyl forms of speech is used to ensure the development of communication skills of schoolchildren, their social adaptation and integration in society.

To ensure effective communication of deaf children at the initial stage of schooling, in addition to written and oral forms of verbal speech, dactyl is used. The use of the dactyl form of speech in the educational process involves the obligatory accompaniment of dactyling by verbal pronunciation of all speech material. The process of fingerprinting is the reproduction of the spelling form of a word by means of the fingers. Thus, using the dactyl form of speech when communicating, students with hearing impairments reproduce complex movements and positions with their fingers, replacing each other. Upon admission to school, children with preschool training already have a fairly large experience in fingerprinting, and, consequently, systematic training of voluntary motor skills of the fingers. Being in elementary school only strengthens these motor skills. We can talk about a positive effect on the development of voluntary motor skills of the fingers of deaf children of using the dactyl form of speech at the initial stage of learning.

Specially organized lessons in sculpting, application, modeling and construction, prototyping, etc., are aimed at developing and improving the motor skills of a deaf child in close connection with his speech development. By organizing the work of deaf schoolchildren, verbal speech becomes not only a means, but also a goal of learning. Younger schoolchildren learn to place material or a template, make markings, draw lines, cut out of paper, cardboard, or other material, carefully glue, sketch, accompanying these actions with speech. In the process of making crafts, schoolchildren with hearing impairments gain knowledge about the world around them, they develop a variety of skills, develop general motor skills and voluntary motor skills of the fingers, and improve their speech activity.

Moreover, the accentuated formation of voluntary motor skills of the fingers of younger schoolchildren with hearing impairment occurs due to their mastery of writing and drawing techniques. Small operations begin to combine into larger activities and gradually turn into complex activities (written speech). In the process of learning to write, combined motor skills are developed, and the child begins to write with one motor act a whole complex of letters. In the process of writing, there is a close interaction of various analyzers of the child: speechhearing, speech-motor, visual, general motor. Insufficient development of any of these analyzer systems causes difficulties in mastering writing. It is obvious that for effective mastering of writing, reading, speaking, a child with hearing impairment requires welldeveloped motor skills that underlie these complex processes.

The mastery of written speech is closely related to the development of the child's oral speech. Formation of a letter is possible only based on a sufficiently high level of its development. Children with significant hearing loss and hearing loss at an early age cannot master oral speech on their own. It can be formed only in the course of systematic correctional work, which is carried out in educational institutions for the deaf in special classes in the correctional educational field. The allocation of significant time in correctional and pedagogical work for the development of oral speech is explained by the recognition of its exceptional importance for the development of a child with hearing impairment. The 
formation of oral speech is carried out in special individual lessons on the formation of speech hearing and the pronunciation side of a deaf child's speech and is carried out by a speech therapist. In the course of special work on oral speech, providing for numerous speech training, practicing the articulatory skills of deaf children. Children perform articulation exercises of varying difficulty, constantly improving the development of the motor sphere. This is due to the need to activate the articulatory apparatus for the subsequent formation of the pronunciation of sounds, words, and phrases. It is obvious that special work on the formation of the oral speech of deaf children and the creation of conditions for its active use in the communication process has a positive effect on the development of their articulatory motor skills.

A specific form of teaching schoolchildren with hearing impairment is musical-rhythmic classes, which combine the musical development of the child, the improvement of oral speech and the active formation of the motor sphere. Specific work is being done to develop precise, expressive, and rhythmic movements. A special place is given to exercises to maintain balance by children with hearing impairment, the development of coordinated movements in them, the formation of skills to relax and strain muscles, etc. The combination of music, movements and oral speech contributes to the development of expressive plasticity and facial expressions in children.

Physical education teacher's lessons of educational, correctional-developmental, healthimproving, therapeutic, sports orientation effectively solve the problems of development and improvement of the motor sphere of deaf junior schoolchildren. Children learn to hold the goal of the movement, perform throws, and catch the ball, master skills in sports games, etc. Physical education for deaf schoolchildren contributes to the formation of basic movements and education of physical qualities, correction of disorders of the musculoskeletal system and the respiratory system, upbringing, and correction of motional-coordinating abilities. The use of various exercises, elements of charging, mobile and sedentary games with children by teachers increases the level of development of their general motor skills.

An effective resource in the work on the formation of motor skills of schoolchildren with hearing impairment are computer technologies used in the educational process. Recently, some researchers have been working on this topic Dorothee Jelsma, Reint H. Geuze, Remo Mombarg, Bouwien C. M. Smits-Engelsman, and others [24].

Information that is presented in a playful way, using animation, attracts the attention of students with hearing impairments and arouses great interest. The use of various modifications of computer simulators, educational games allow you to purposefully form, develop and improve the motor skills of a deaf primary school student. Researchers point out the effectiveness of using a number of computer simulators for the development of general motor skills of the child and voluntary motor skills of the fingers (Stabiloplatform in the computer version of the simulator - Wii-Fit; Multimedia steering wheel; PlayStation Move; Cyberduyball; Xbox, etc.), as well as for the development of articulatory motor skills (speech therapy simulator "Delfa-142", hardware-software complex "Visible speech - III", computer game "Development of speech. Learning to speak correctly", computer game "Games for Tigers", educational computer program "Articulation pattern of sounds is normal", computer speech therapy complex "Visual pronunciation trainer", etc.) [24, 25]. The use of computer simulators in the educational information environment of the school for the deaf will help to diversify the game forms of conducting physical education classes, as well as to dose psychomotor loads in accordance with the individual characteristics of children. In the lessons of the correctional and educational area (individual lessons on the formation of speech hearing and the pronunciation side of oral speech), computer speech therapy simulators help in the development, correction, and improvement of articulation skills necessary for the successful formation of oral speech in deaf students. 
Thus, school educational institutions for deaf children have all the means to carry out successful systematic purposeful work on the development of all aspects of the child's personality, and comprehensively solve the problems of identifying and correcting developmental disorders, including disorders of the motor sphere.

\section{Conclusion}

Our analysis of violations of the motor sphere of primary schoolchildren with hearing impairment showed the undoubted urgency of this problem. In modern scientific research, violations of all components of the motor sphere of deaf schoolchildren are considered: general motor skills, voluntary motor skills of the fingers, articulatory motor skills. An equally important aspect is the connection between auditory deprivation and impairment of the vestibular system, because of which specific difficulties in mastering motor skills by younger deaf schoolchildren are revealed. The positive influence of correctional and developmental work, which is carried out at the first stage of education, in schools for deaf children, has been determined. An effective resource for the development of the motor sphere of children with hearing impairment is the creation of an information and educational environment at school, the content of which includes computer simulators, educational games, and developing computer programs. These results indicate the need to continue improving the work on the successful development of the psychomotor sphere of junior schoolchildren with hearing impairments studying in educational institutions for deaf children.

\section{References}

1. N.I. Stepanchenko, I.B. Hrybovska, M.V. Danylevych, R.V. Hryboskyy, Pedagogy of Physical Culture and Sports 24, 151-156 (2020). doi: 10.15561 / 26649837.2020.0308.

2. Esther Hartman, Suzanne Houwen, Chris Visscher, Adapted physical activity quarterly: APAQ 28, 132-45 (2011). doi: 10.1123/apaq.28.2.132.

3. F. Gheysen, G. Loots, H. Van Waelvelde, Journal of Deaf Studies and Deaf Education Spring 13 (2), 215-24 (2008). doi: 10.1093/deafed/enm053.

4. M. Sokolov, K.A. Gordon, M. Polonenko, S.I. Blaser, B.C. Papsin, S.L. Cushing, Hear Res Feb 372, 52-61 (2018). doi: 10.1016/j.heares.2018.03.032.

5. J. Lee, T.Y. Ching, K. Crowe, L. Capples, V. Marnein, M. Sito, J Deaf Stud Deaf Educ October 20 (4), 331-42 (2015). doi: 10.1093/deafed/env028.

6. Pt Phd Rajendran, Venkadesan Roy, Finita, Italian journal of pediatrics Jul 14 (2011). doi: 10.1186/1824-7288-37-33.

7. H. Hasanbegović, S. Mehmedinović, H.E. Mahmutović, J Spec Educ Rehab 11(3-4), 715 (2010).

8. M.S. Houde, S.P. Landry, S. Pagé, M. Maheu, F. Champoux, Neural Plast Jan 12 (2016). doi: 10.1155/2016/5260671.

9. R.S. Melo, Gait Posture Sep 57, 109-114 (2017). doi: 10.1016/j.gaitpost.2017.05.031.

10. G. Leigh, T.Y. Ching, K. Crowe, L. Cupples, V. Marnane, M. Seeto, J Deaf Stud Deaf Educ Oct. 20 (4), 331-42 (2015). doi: 10.1093/deafed/env028.

11. J. Vitkovic, C. Le, S.L. Lee, R.A. Clark, Audiol Neurootol 21 (4), 195-202 (2016). doi: 10.1159/000445100.

12. P. Ochoa Martínez, Revista Brasileira de Educação Especial Oct., 26 (4), 567-570 (2020). https://doi.org/10.1590/1980-54702020v26e0063. 
13. R.M. Kamel, S.M. Mounir, M.A. Elbedewy, M.M. Essa, L.A. Fergany, E.S. Mehrem, NeuroRehabilitation Jan. 23 (2021). doi: 10.3233/NRE-201589.

14. D.L. Horn, D.B. Pisoni, R.T. Miyamoto, Laryngoscope Aug. 116 (8), 1500-6 (2006). doi: 10.1097/01.mlg.0000230404.84242.4c.

15. Zahra Soori, Ali Heyrani, Forouzan Rafie, Sport Sciences for Health Dec. 15 (4) (2019). doi: 10.1007/s11332-019-00564-y.

16. N. Baudonck, K. Van Lierde, I. Dhooge, P. Corthals, Folia Phoniatr Logop 63 (3), 15460 (2011). doi: 10.1159/000318879.

17. N. Baudonck, I. Dhooge, E. D'haeseleer, R. Van Lierde, Int J Pediatr Otorhinolaryngol Apr. 74 (4), 416-21 (2010). doi: 10.1016/j.ijporl.2010.01.017.

18. G.G. Egiazaryan, K.V. Sudakov, J Hist Neurosci Jan-Jun. 16 (1-2), 194-205 (2007). doi: 10.1080/09647040600602805.

19. E. Verbecque, T. Marijnissen, N. De Belder, V. Van Rompaey, A. Boudewyns, P. Van de Heyning, L. Vereeck, A. Hallemans, Int J Audiol. Jun. 56 (6), 361-381 (2017). doi: 10.1080/14992027.2017.1281444.

20. R.S. Melo, S.E.D.S. Marinho, M.E.A. Freire, R.A. Souza, H.A.M. Damasceno, M.C.F. Raposo, Einstein (Sao Paulo) Jul-Sep. 15 (3), 262-268 (2017). doi: 10.1590/S167945082017AO3976.

21. P.Y. Ochoa-Martínez, Revista Brasileira de Educação Especial 26 (4), 567-570. (2020) https://doi.org/10.1590/1980-54702020v26e0063.

22. C. Barboza A. Ramos, P. Abreu, H. Castro, Creative Education Jan 10 (04), 714-725 (2019). doi: 10.4236/ce.2019.104053.

23. D. Jelsma, R.H. Geuze, R. Mombarg B.C. Smits-Engelsman, Hum Mov Sci Feb. 33, 40418 (2014). doi: 10.1016/j.humov.2013.12.007.

24. M. Skuratovskaya, E. Klimkina, E3S Web of Conferences 210, 18043 (2020) ITSE2020. https://doi.org/10.1051/e3sconf/202021018043

25. M. Skuratovskaya, N. Manohina, M. Ianovskii, S. Dzura, E3S Web of Conferences 210, 18042 (2020). ITSE-2020. https://doi.org/10.1051/e3sconf/202021018042 